\title{
Explaining Welfare Benefits in the South: A Regional Analysis
}

\author{
David A. Breaux, John C. Morris, and Rick Travis
}

This paper examines the choices made by states in the implementation of the Personal Responsibility and Work Opportunity Reconciliation Act of 1996. Commonly known as TANF, the legislation gives states substantial control over the choices of benefits and sanctions they impose on program recipients. Using the models and theoretical explanations offered by Soss et al. (2001) and tested in a 49-state model, we test the degree to which these explanations hold when applied to a regional analysis of southern states. We find that the southern states are similar to the rest of the country when it comes to setting TANF benefit choices, although social control explanations are more important for southern states than for the rest of the nation.

Recent developments in American public policy and federalism have included a renewed interest in the devolution of program authority to state governments. Driven by both ideological and resources arguments, the late 1980s and 1990s witnessed a flurry of legislative activity to return control of federal programs to state governments in a variety of policy areas. One of the most visible examples of this move to devolution is the Personal Responsibility and Work Opportunity Reconciliation Act of 1996 (PRWORA), the legislation that replaced a federally-administered entitlement program (Aid for Families with Dependent Children, or AFDC) with a block grant program designed to give states significant flexibility not only over the administration of the program, but also significant freedom to select from a series of policy tools available to "customize" the program to the needs of the individual state. Known as the Temporary Assistance for Needy Families (or TANF) program, the policy theory includes incentives to reduce welfare caseloads, promote job training and employment, and end welfare dependency (Nathan and Gais 1999).

This paper builds on previous analyses by both Breaux et al. (2002; 2000; 1998), and Soss et al. (2001). ${ }^{1}$ Using the models developed Soss et al., we seek to discover whether the explanations reported by Soss et al. in a 49state model for the differences in state policy choices under TANF hold when applied to a regional analysis of the South. If V.O. Key (1949) is correct in his assessment that southern politics are truly unique, we should

\footnotetext{
DAVID BREAUX is professor and head of the Department of Political Science and Public Administration at Mississippi State University. John C. Morris is an associate professor of public administration at Old Dominion University. RICK TRAVIS is an associate professor in the Department of Political Science and Public Administration at Mississippi State University.
}

The American Review of Politics, Vol. 28, Spring, 2007: 1-18

(C)2007 The American Review of Politics 
expect to detect differences in the factors that explain state policy choices between southern states and the rest of the country.

The TANF program provides a unique and important opportunity for students of policy, in that the timing of implementation of the TANF program was largely simultaneous in all states. While a vast literature on implementation has catalogued significant variations in implementation timing across an array of federal programs, TANF was implemented by all states within a very short period of time. From the standpoint of policy research, the usual problems of conducting state-level cross-sectional research and the problems of implementation timing are largely nonexistent. Following Soss et al., we also seek to assess the variety of theories available that purport to explain the policy choices made by states. However, if the South as a region is truly different, we should expect differences in the explanatory abilities of some (or all) of the theories tested in the earlier work.

\section{A Brief History of Welfare Reform}

The issue of welfare reform has been at the forefront of the American national political scene for several years. Driven by an ideological shift in the population and realized by electoral outcomes in the 1990s that shifted control of Congress and saw the elections of a cadre of Republican state governors, welfare reform became the focus of attention of the conservative movement. Coupled with ideals of decentralized government, a smaller, leaner national government, and increased policy authority for states (Breaux et al. 2002), the movement toward welfare reform proved an easy target for those wishing to alter "business as usual." The call for welfare reform also received an important boost from other quarters: Bill Clinton had promised to "end welfare as we know it" during his successful 1992 presidential campaign, and spending for AFDC reached a peak in 1994 (Burke 1997). Although there was general agreement among policy makers that the existing welfare system was in need of repair, liberals and conservatives differed significantly about how to go about it (Breaux et al. 2002).

Previous work by Breaux et al. $(1998 ; 2002)$ has concluded the pattern for what would eventually become TANF was already in place in several states, operating under the guise of waiver packages to AFDC. In particular, the waiver package approved for Mississippi in 1994 and put into place as the Work First pilot program in Mississippi (Breaux et al. 1998) was nearly identical to the provisions written into the national TANF law in 1996. Emboldened by their electoral victories in 1994, the Republican-led Congress began work to draft new legislation. Included in the new law were several important provisions. First, funding for the program would now be available in block grant form, to be disbursed to states using a grant formula. Second, 
state programs must include a provision requiring work effort and job training for TANF recipients. Third, citizens would only be eligible to receive benefits under TANF for a maximum of 60 months during their lifetime. Fourth, states could impose a limit on the number of family members eligible to receive TANF benefits (called a family cap). The legislation moved reasonably quickly through Congress, and was signed into law by President Clinton in 1996.

In sum, an important feature of the law gives states the authority to set the terms of welfare relief. While the federal law sets maximum limits for the strength of the allowable sanctions, states are free (within those limits) to choose their own terms, and to design their programs to fit their perceived needs. To date, a significant body of work exists that suggests states have, in fact, tailored their programs to fit their particular circumstances or requirements (see, for example, Breaux et al. 2000; Liebschutz 2000; Mettler 2000; and Rector and Youssef 1999), and that states have tended toward program designs that are both punitive and restrictive (Mettler 2000).

\section{State Policy Choices Under TANF}

Because TANF was conceived as a block grant program, the law gives states a considerable amount of latitude to design their TANF program to fit their own needs. In this regard, states may choose program requirements across a range of options set forth in the law. The specific choices made by states can thus be considered to be a function of the circumstances unique to each state.

The first area of choice involves work requirements. While Gilens (1999) notes that the notion of work requirements have been a part of the welfare policy scene for many years, few states actually imposed work requirements until TANF. ${ }^{2}$ The inclusion of a work requirement in the new law reflects a desire to demand an obligation to work in return for public assistance. States are free under TANF to set requirements for work that are more or less strict than the federal requirement of 24 months. Second, a desire by lawmakers to end welfare dependence led to the inclusion of a lifetime cap on the number of months a person is eligible to receive TANF assistance. Driven by stories of multiple generations of families dependent on public assistance, Congress imposed a lifetime limit of 60 months of eligibility for TANF assistance. States are free to impose even shorter limits if they choose.

The third area of choice involves the reproductive behavior of women, one of the most widely debated features of the legislation (Soss et al. 2001, 380). Specifically, states are free to impose a "family cap" that denies additional benefits for children born into families already receiving assistance. 
The goal is to provide a negative incentive to TANF recipients who might be tempted to bear children as a means to increase their benefit levels. Finally, those advocating welfare reform wanted a program that would provide enough "clout" to ensure compliance with the requirements of the program. States are free to choose a sanction policy from a range of options to entice compliance from TANF recipients.

\section{Explaining State Policy Choices}

A number of different theoretical perspectives exist that purport to explain why states make the policy choices they do. Because we are testing the work of Soss et al. (2001), we present the six different theoretical perspectives offered in the previous work. These perspectives include explanations for state choices as the result of electoral conflict, ideological conflict, policy innovation activities, social control, moral problem-solving, and race conflict. Where we believe a different hypothesis is appropriate in our regional analysis, those differences are noted.

\section{Social Control Explanations}

The social control approach analyzes welfare systems as a means to maintain social order, particularly among marginal populations (Suttles and Zald 1985; Mizruchi 1983). Following the work of Piven and Cloward (1993), Soss et al. (2001) suggest that welfare policies are used as a means of reducing pressure on the political system and bolstering state legitimacy by extending relief to these marginal populations during times of a lackluster economy or of civil unrest. On the other hand, a strong economy, such as that seen during the 1990s, creates additional pressures on labor markets, and thus additional pressures on states to reduce welfare dependency and move people on public assistance into the labor market to reduce that pressure. If this explanation is accurate, we would expect to see more stringent TANF requirements in states with tighter labor markets, particularly policy choices that address the work requirements of TANF.

A second social control explanation is drawn from the use of more formal mechanisms to enhance social order (Soss et al., 2001, 384). In this explanation, states that rely on "institutional tools" such as incarceration (or mandatory sentencing, imposition of inmate work requirements, etc.) as a means to enforce social order are more likely to orient efforts in other policy areas (such as welfare) toward a stricter regime of sanctions. Thus, states with larger increases in incarceration rates in the six years preceding TANF are more likely to adopt stricter TANF sanctions. 
Because the South is a bastion of traditionalistic political culture (see Elazar 1984; see also Breaux et al. (2000a) for an analysis of welfare benefits in southern states), we would expect social control hypotheses to be important explanators of state policy choices for southern states. A traditionalistic political culture places a great deal of emphasis on maintenance of the status quo (the existing social order). Coupled with a strong political emphasis on "law and order" in the southern states, we expect social control explanations to be important in our analyses.

\section{Ideological Conflict}

The thrust of this theoretical argument is that states have historically different orientations toward the proper role of government in society, and the role of government in securing a sense of social well-being. Previous work by Breaux et al. (2000) and Breaux and Morris (2001) links the concept of political culture to the amount of TANF cash assistance offered by states. While political culture encompasses more in conceptual terms than political ideology, the fundamental arguments are not dissimilar.

For Soss et al. $(2001,382)$, the hypotheses suggested by this approach are drawn from two competing explanations: that states are more likely to adopt an incremental approach (Lindblom 1959) to avoid backlash, or that states that were more restrictive under AFDC will strengthen the sanctions imposed under TANF. Another explanation offered by Soss et al. is that the ideological positions of current state officials will determine the kinds of choices made under TANF; states with more liberal-leaning governments are more likely to adopt less restrictive TANF policies. Based on the experiences of Mississippi at the time of TANF implementation (see Breaux et al. 1998), we expect these hypotheses to be important in explaining state policy choices in the South.

\section{Policy Innovation Explanations}

A third potential explanation views state policy choices made under TANF as the result of a process of the spread of innovation among states (Walker 1969; Gray 1973; among others). While state choices are constrained by federally-imposed limits found within the PRWORA, the argument is that states are still free to innovate within those bounds, and states that choose strict TANF requirements are thus taking a very different path than most states developed under AFDC. States that show a willingness to innovate are more likely to adopt more stringent TANF requirements. Soss et al. measure policy innovation in this case by coding the earliest date each state requested any waiver under the AFDC program, between 1977 and 
1996. While Mississippi was ultimately an important innovator of welfare reform, their efforts did not occur until the early 1990s. Furthermore, southern states are not generally known as strong innovators; we do not expect innovation to be important in our analyses.

\section{Race Conflict Explanations}

The tradition of race relations and their role in shaping welfare politics in the United States is significant. Beginning with the Social Security Act of 1935, discussions of race have been part and parcel of welfare policy debates, and programs identified as benefiting non-white stakeholders are more likely to be subject to popular hostility and punitive sanctions (Soss et al., 2001, 384). More recently, work by Orr (1976), Wright (1976), and Howard (1999) have found a relationship between the percentage of African-Americans on AFDC rolls and the size of the AFDC benefit available in a state.

Another approach to the race conflict explanation is found at the individual level. A significant body of evidence exists that suggests individual racial attitudes and opinions have a measurable impact on attitudes about welfare policy. Attitudes reflecting racial resentment among whites are strongly correlated with attitudes about welfare policies (Kinder and Sanders 1996), and many whites tend to overestimate the percentage of welfare recipients who are black (Soss et al.), a view often reflected in the popular media. Soss et al. $(2001,384)$ thus rightly conclude that race and welfare politics are "deeply intertwined."

There are two hypotheses drawn from this theoretical approach offered by Soss et al. The first is that states with a higher percentage of AfricanAmericans in the AFDC caseload are more likely to adopt stricter TANF policies. In addition, Gilens (1999) suggests that the significant recent growth in the nation's Hispanic population may lead Hispanics to be associated with the negative aspects of welfare policy. Thus, the larger the percentage of Hispanics in the AFDC caseload, the more strict TANF policies will be.

While this latter hypothesis may be accurate for all states, the percentage of Latinos in the southern states is relatively small. Outside of Florida, significant Hispanic populations are limited to the border states (Texas, New Mexico, Arizona, and Florida) and traditional "melting pot" cities and states. On the other hand, attitudes about race in the southern states are likely to reflect those of policy makers in the states. While African-Americans have made significant gains in achieving elected office in many southern states, it is doubtful those gains are strong enough to overcome the more traditional attitudes of the white power structure in state politics, particularly in an era 
in which conservative attitudes are on the rise. We would therefore expect to find significant support for the first of these two hypotheses, and little support for the second. In fact, we suspect race is so important in the southern states that the issue of race may well drive the significance of the race variable for all states.

\section{Moral Problem-Solving}

The crux of the moral problem-solving argument is that liberal welfare policies encourage anti-social and irresponsible behavior, in that recipients of welfare benefits adopt behaviors that take advantage of the largesse of society, and over time become dependent on that largesse at the expense of personal (and social) responsibility. By adopting a more paternalistic (strict) approach to welfare policy, poor people would be encouraged to embrace a sense of personal responsibility, a more moral position.

This theoretical position is bolstered by the significant increase in AFDC rolls (Mead 1992; 1997) in the years prior to TANF implementation. Furthermore, as the conservative right became more emboldened by their electoral victories in the 1990s, the related concepts of "illegitimacy" and "dependency" (Soss et al., 2001, 382) gained legitimacy as part of the political discourse of the time. More importantly, it is not necessary for the discourse to be empirically tested, but simply believed by enough people. At the same time, policymakers (and those participating in the political discourse) may indeed respond to actual conditions, and thus adopt tougher (more restrictive) policies. Soss et al. offer two hypotheses under this framework: states with higher caseload-to population ratios under AFDC (a general indicator of the degree of "immoral" behavior) are more likely to adopt strict TANF policies. The second hypothesis suggests that states with higher percentages of births to unwed mothers are more likely to adopt more restrictive TANF policies. While Soss et al. point out the lack of an immediate link to the illegitimate birth rate and work requirements or time limits, there may indeed be a much more direct link to the imposition of a family cap (a policy to regulate reproductive behavior) and sanction policy (a more general punitive measure). However, we do not expect the southern states to differ from non-south states on these measures.

\section{Electoral Conflict}

The theoretical tradition deriving explanation for state policy choices from state electoral politics is drawn from two characteristics of state politics. First, the amount of inter-party competition present in a state is important. Founded in the work of V.O. Key (1949), the argument is that policy 
outcomes are more likely to favor the needs of disadvantaged citizens in situations where party competition is high. Political parties are thus more likely to agree to policies that directly benefit the disadvantaged in an effort to gain votes at the margins. Recent work by Brace and Jewett (1995) and Holbrook and Van Dunk (1993) support this thesis. Following Soss et al. (2001, 383), we will test the hypothesis that states with more evenly matched two-party systems are more likely to adopt less strict TANF policies. Because of the recent growth in two-party competition in southern states, we do not expect this explanation to differ between southern states and the non-South.

A second characteristic is determined by the numbers of low-income voters. A stronger turnout of low-income voters in an election should sway policy makers to respond to the needs of this constituency. States with larger numbers of low-income voters should thus be more likely to adopt more liberal welfare policies. As before, there is sufficient recent evidence to support this hypothesis (see Hill, Leighley, and Hinton-Anderson 1995; Hicks and Swank 1992; among others).

\section{Methods}

Each of the hypotheses developed in the preceding section is operationalized and tested in the models presented in the following section. Because we are testing to determine if the findings of Soss et al. (2001) hold in a regional analysis, we employ the same measures of each of the variables in the original work (and, as mentioned earlier, the same dataset). The five dependent variables include broad measures of stringency of sanctions, and four component measures of sanction policy. The first dependent variable is an additive index in which states receive additional points for adopting sanctions less than the maximums allowed under the law, producing an ordinal measure ranging from one to four in value. The second dependent variable is an ordinal measure that captures the overall strength of sanctions adopted by states, ranging from one to three. The last three dependent variables measure component elements of sanctions policy - work requirements, time limits, and family cap, coded dichotomously. States that have adopted policies more strict than the federal minimum are coded " 1 ;" others are coded " 0. ." Following Soss et al., we employ ordered logistical regression for the models using ordinal dependent variables (measures of overall policy outcomes and the measure of strength of sanctions) and binary logistical regression for the two models with dichotomous dependent variables (stricter work requirements, stricter time limits, and family cap). The data set includes 49 cases; Nebraska is omitted from the analysis. 
The models tested include ten independent variables which operationalize the six different theoretical perspectives. All of the independent variables are measured at the interval level. The independent variables categorized under their theoretical perspectives are as follows:

$\begin{array}{ll}\text { Social Control } & \text { - unemployment rate } \\ & \text { - change in incarceration rate } \\ \text { Ideological Conflict } & \text { - government ideology } \\ \text { Policy Innovation } & \text { - welfare innovation } \\ \text { Race Conflict } & \text { - percent African-American in AFDC caseload } \\ & \text { - percent Latino in AFDC caseload } \\ \text { Moral Problem-Solving } & \text { - caseload to population ratio } \\ & \text { - unmarried birth rate } \\ \text { Electoral Conflict } & \text { - inter-party competition } \\ & \text { - low-income voter turnout. }{ }^{3}\end{array}$

In order to detect regional differences, our analyses include two sets of models. First, we present the five 49 -state models presented by Soss et al. (2001). ${ }^{4}$ Next, we add five additional independent variables that allow us to measure the distinctive impact that we expect for the southern states. ${ }^{5}$ As noted in the discussion above, we hypothesize that the effects of the unemployment rate, changes in incarceration rates, government ideology, welfare innovation, and the percent of African-American in the AFDC caseload have differential impacts for the non-south states compared to the southern states. By calculating the interaction of these five variables with a dummy variable measuring the south and adding only the interactive terms in our second set of models we are able to sort out distinctions between the south and nonsouth concerning the determinants of welfare policy sanctions.

\section{Analyses}

Our first model employs a dependent variable that measures the stringency of TANF policy outcomes (Table 1). For the 49-state model, Soss et al. find that only the percent of African-Americans on the AFDC rolls and government ideology are statistically significant. ${ }^{6}$ Furthermore, the pseudo $\mathrm{R}^{2}$ is a modest .144. In the distinct South model however, we find support for two of our hypotheses and a distinct contrast with a third. Both of the variables operationalizing the social control perspective are significant for the southern states while they have no relationship for the rest of the nation. Although, for most of the country, changes in the likelihood of a state adopting more stringent policy outcomes are not related to shifts in the unemployment and incarceration rates, this is not the case for the southern 
Table 1. State Policy Choices as a Single Dimension

\begin{tabular}{|c|c|c|c|c|}
\hline & \multicolumn{4}{|c|}{ Stringent Policy Outcomes (ordered logit) } \\
\hline & \multicolumn{2}{|c|}{ Soss Replication } & \multicolumn{2}{|c|}{ Distinct South Mode } \\
\hline & Coeff. & L.R. test & Coeff. & L.R. test \\
\hline unemployment rate & \multirow[t]{2}{*}{-.336} & \multirow[t]{2}{*}{.760} & -.069 & .030 \\
\hline South * unemployment rate & & & 6.123 & $5.01 * *$ \\
\hline change in incarceration rate & \multirow[t]{2}{*}{.003} & \multirow[t]{2}{*}{.040} & -.005 & .090 \\
\hline South * change in incarceration rate & & & .441 & $9.49 * * *$ \\
\hline government ideology & \multirow[t]{2}{*}{-.027} & \multirow[t]{2}{*}{$4.32 * *$} & -.042 & $8.13 * * *$ \\
\hline South * government ideology & & & .213 & $11.08 * * *$ \\
\hline welfare innovation & \multirow[t]{2}{*}{-.023} & \multirow[t]{2}{*}{.200} & -.084 & 1.91 \\
\hline South $*$ welfare innovation & & & .067 & .160 \\
\hline percent African-American & \multirow[t]{2}{*}{.043} & \multirow[t]{2}{*}{$7.36^{* * *}$} & .034 & $3.09 *$ \\
\hline South * percent African-American & & & .044 & 1.59 \\
\hline percent Latino & .039 & 2.28 & .047 & 2.57 \\
\hline caseload-to-population ratio & -.265 & .640 & -.605 & $2.80^{*}$ \\
\hline unmarried birth rate & -.034 & .140 & .002 & .000 \\
\hline inter-party competition & -.951 & .270 & -1.967 & .700 \\
\hline low-income voter turnout & -7.216 & 1.04 & -7.520 & .780 \\
\hline intercept 1 & \multicolumn{2}{|l|}{-1.544} & \multicolumn{2}{|l|}{-1.477} \\
\hline intercept 2 & \multicolumn{2}{|l|}{.278} & \multicolumn{2}{|l|}{.661} \\
\hline intercept 3 & \multicolumn{2}{|l|}{1.455} & \multicolumn{2}{|l|}{2.085} \\
\hline intercept 4 & \multicolumn{2}{|l|}{2.728} & \multicolumn{2}{|l|}{4.368} \\
\hline Model LR & \multicolumn{2}{|c|}{$\begin{array}{l}\Pi^{2}(10 \mathrm{df})=22.02 \\
\text { pseudo } \mathrm{R}^{2}=.144\end{array}$} & \multicolumn{2}{|c|}{$\begin{array}{c}\Pi^{2}(15 \mathrm{df})=44.306 \\
\text { pseudo } \mathrm{R}^{2}=.291\end{array}$} \\
\hline
\end{tabular}

states. The results in Table 1 indicate a clear, positive link between increases in these rates and the likelihood of a southern state adopting more stringent welfare policies.

Concerning the relationship between government ideology and welfare stringency, the results for the non-south states continues to indicate a negative relationship between levels of liberalism and the likelihood of having more stringent policies. For the south, however, the relationship is positive. In fact, the most liberal southern states, Arkansas, Florida, Georgia, and North Carolina all adopted rather stringent policies while some of the most conservative, Alabama, Mississippi, and Louisiana, opted for less restrictive policies. An immediate explanation for this is not obvious. Perhaps this is related to the most conservative states also being the poorest and having the 
largest number of citizens dependent on welfare benefits, thus making for larger societal problems if the outcomes of reform are negative. It is also the case that these conservative states are the most traditionalistic and one characteristic of traditional culture is resistance to innovation. In any event, this finding is very interesting and suggests that more consideration should be paid to policy changes within the south over the last quarter century.

We also note that the percentage of African-Americans on AFDC rolls remains statistically significant for the nation as a whole and the non-significant result for the South* percent African-American coefficient indicates that the south follows this national pattern. Still, like Soss et al., we find weak support for the use of a single, ordered dimension to explain state policy choices, in that the relative weakness of the model does little to further our understanding of state TANF policy choices, for either all states or the South.

\section{Analyzing Separate Dimensions of State Policy Choices}

Our second set of analyses examines the different dimensions possible for state choices of TANF sanctions. In this analysis we employ a series of four dependent variables, each representing a different facet of state policy choices. Table 2 presents an ordered logistical regression model using the "strength of sanctions" dependent variable (coded weak, moderate, and strong). Similar to the results from Table 1 we find that the social control variables are very important for southern states but have no significance for the rest of the country. Earlier work by Breaux et al. (2000; 2000a) found political culture to be a strong indicator of the amount of the TANF cash benefit, even among southern states. Using Elazar's measure of political culture, most southern states are strongly traditionalistic; a facet inherent in the concept of traditionalistic political culture is a strong desire for social control and maintenance of the existing social order. We believe the findings presented here are consistent with this explanation.

Compared to Table 1, we also find similar results for the impact of government ideology, where liberalism decreases the likelihood of stronger sanctions for the bulk of the country but increases that likelihood for the south, and the impact of the percent of African-Americans on the AFDC rolls, which shows a nationally consistent, positive impact of the likelihood of adopting stronger sanctions. For the welfare innovation hypothesis we also find that the south is similar to the rest of the nation where states that requested earlier AFDC waivers were more likely to adopt stricter sanctions.

We next turn our attention to the second dimension of TANF choices; stricter work requirements. Under PRWORA, states may choose to impose a work requirement stricter than the federal requirement of 24 months. Twenty-six states chose to do so; the remaining states chose a work require- 
Table 2. State Policy Choices Analyzed as Separate Dimensions:
Strength of Sanctions

\begin{tabular}{|c|c|c|c|c|}
\hline & \multicolumn{4}{|c|}{ Strength of Sanctions (ordered logit) } \\
\hline & \multicolumn{2}{|c|}{ Soss Replication } & \multicolumn{2}{|c|}{ Distinct South Model } \\
\hline & Coeff. & L.R. test & Coeff. & L.R. test \\
\hline unemployment rate & \multirow[t]{2}{*}{.333} & \multirow[t]{2}{*}{.550} & .897 & 2.40 \\
\hline South * unemployment rate & & & 7.542 & $7.73 * * *$ \\
\hline change in incarceration rate & \multirow[t]{2}{*}{.010} & \multirow[t]{2}{*}{.340} & -.003 & .020 \\
\hline South * change in incarceration rate & & & .484 & $11.73 * * *$ \\
\hline government ideology & \multirow[t]{2}{*}{-.055} & \multirow[t]{2}{*}{$10.94 * * *$} & -.081 & $13.84 * * *$ \\
\hline South * government ideology & & & .104 & $2.950 *$ \\
\hline welfare innovation & \multirow[t]{2}{*}{-.202} & \multirow[t]{2}{*}{$9.24 * * *$} & -.288 & $11.04 * * *$ \\
\hline South $*$ welfare innovation & & & -.074 & .0150 \\
\hline percent African-American & \multirow[t]{2}{*}{.039} & \multirow[t]{2}{*}{$4.87 * *$} & .046 & $3.70 *$ \\
\hline South * percent African-American & & & .026 & .330 \\
\hline percent Latino & -.019 & .440 & -.015 & .190 \\
\hline caseload-to-population ratio & -1.319 & $11.82 * * *$ & -2.183 & $18.28 * * *$ \\
\hline unmarried birth rate & .188 & $3.14 *$ & .228 & $2.91 *$ \\
\hline inter-party competition & -5.441 & $5.91 * *$ & -7.051 & $6.41 * *$ \\
\hline low-income voter turnout & -10.094 & 1.15 & -16.540 & 1.44 \\
\hline \multirow{2}{*}{$\begin{array}{l}\text { intercept } 1 \\
\text { intercept } 2\end{array}$} & \multirow{2}{*}{\multicolumn{2}{|c|}{$\begin{array}{r}-1.394 \\
2.111\end{array}$}} & \multicolumn{2}{|l|}{-1.479} \\
\hline & & & \multicolumn{2}{|l|}{3.094} \\
\hline Model LR & \multicolumn{2}{|c|}{$\begin{array}{l}\Pi^{2}(10 \mathrm{df})=39.75 \\
\text { pseudo } \mathrm{R}^{2}=.376\end{array}$} & \multicolumn{2}{|c|}{$\begin{array}{l}\Pi^{2}(15 \mathrm{df})=53.75 \\
\text { pseudo } \mathrm{R}^{2}=.509\end{array}$} \\
\hline
\end{tabular}

ment that meets the federal minimum. Six of the 26 states adopting a stricter work requirement are southern states.

In these models we detect only marginal differences between the Soss et al. replication model and the distinct south model (Table 3). Government ideology is insignificant in the full model, but we again find the contrasting relationship when we allow a distinction between the south and non-south. We also find that the significant relationships found for the social control measures disappears in the distinct south model.

The next dimension of TANF state policy choices addresses the use of time limits (Table 4). Under the TANF law, states may set a lifetime limit on the number of months a person is eligible to receive TANF assistance, up to a maximum of 60 months. While 29 states set their time limit at the 


\section{Table 3. State Policy Choices Analyzed as Separate Dimensions: Work Requirements}

\begin{tabular}{|c|c|c|c|c|}
\hline & \multicolumn{4}{|c|}{ Stricter Work Requirements (binary logit) } \\
\hline & \multicolumn{2}{|c|}{ Soss Replication } & \multicolumn{2}{|c|}{ Distinct South Model } \\
\hline & Coeff. & L.R. test & Coeff. & L.R. test \\
\hline unemployment rate & -1.048 & $3.97 * *$ & -1.054 & 2.12 \\
\hline South * unemployment rate & & & 6.38 & .000 \\
\hline change in incarceration rate & .051 & $4.15^{* *}$ & .038 & 1.96 \\
\hline South * change in incarceration rate & & & 1.915 & .000 \\
\hline government ideology & -.022 & 1.87 & -.040 & $4.78 * *$ \\
\hline South * government ideology & & & 1.321 & $8.92 * * *$ \\
\hline welfare innovation & -.078 & 1.43 & -.104 & 1.55 \\
\hline South $*$ welfare innovation & & & 1.312 & .000 \\
\hline percent African-American & -.017 & .680 & -.050 & 2.56 \\
\hline South * percent African-American & & & .095 & .000 \\
\hline percent Latino & -.006 & .029 & -.001 & .001 \\
\hline caseload-to-population ratio & .087 & & .180 & 109 \\
\hline unmarried birth rate & .040 & .107 & .060 & .138 \\
\hline inter-party competition & -.617 & .071 & .729 & .053 \\
\hline low-income voter turnout & -2.95 & .081 & -4.964 & .115 \\
\hline \multirow[t]{2}{*}{ intercept } & \multicolumn{2}{|l|}{.177} & \multicolumn{2}{|l|}{-.496} \\
\hline & \multicolumn{2}{|c|}{$\begin{array}{c}\Pi^{2}(10 \mathrm{df})=21.09 \\
\operatorname{PRE}=.63\end{array}$} & \multicolumn{2}{|c|}{$\begin{array}{c}\Pi^{2}(15 \mathrm{df})=34.94 \\
\operatorname{PRE}=.67\end{array}$} \\
\hline${ }^{*} \mathrm{p}<.10 ; * * \mathrm{p}<.05 ; * * * \mathrm{p}<.01$ & & & & \\
\hline
\end{tabular}

maximum allowed under the law, 21 states adopted shorter time limits; eight of the states adopting stricter time limits are southern states. For the original model, the use of stricter time limits is driven entirely by race. For the distinct south model, however, only one of the race variables (percent of Latinos on the AFDC rolls) is statistically significant, and the variable representing African-American race attitudes fails to achieve significance. Because Florida is the only southern state with a significant percentage of Latinos in the population, we would not expect issues of Latinos and race to be a significant issue in the southern states.

We do find two other variables that have a distinct effect for southern states only. In the south, those states that are the least liberal ideologically and states that were early to ask for AFDC waivers are the ones least likely to adopt stricter time limits. Specifically, however, it is only Alabama and 
Table 4. State Policy Choices Analyzed as Separate Dimensions: Time Limits

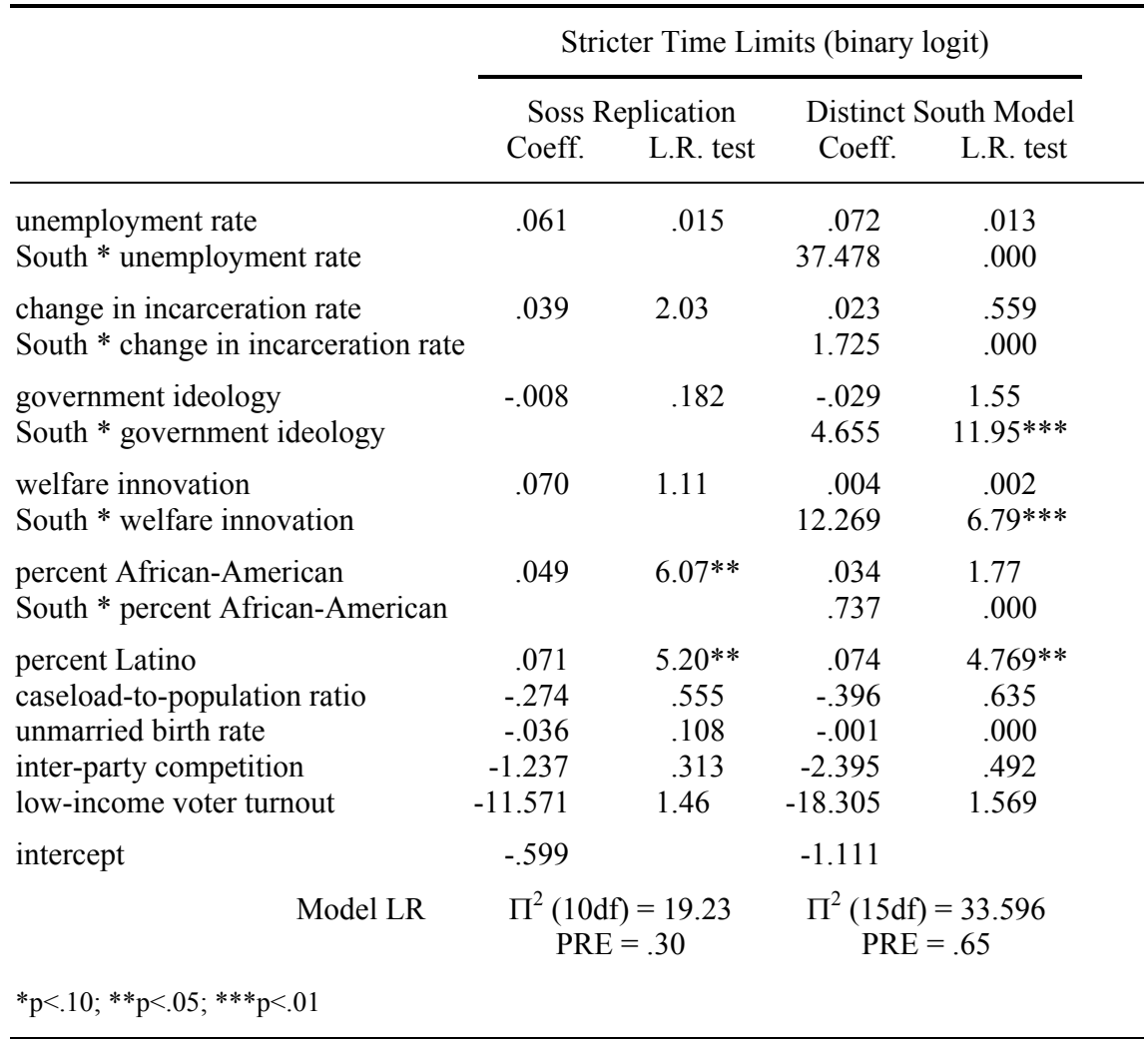

Mississippi among the southern states that failed to adopt time limits. This again points to the distinction within southern states. That the poorest and most culturally conservative states opted to pursue a slower and less extensive welfare reform path continues to point to the south as a unique region. Perhaps this is one of the distinctions between the "old" and the "new" south.

Our last model employs the use of a family cap as the dependent variable. States have the ability to set limits on the number of children in a family for which assistance may be received; if additional children are born, no additional assistance is provided. Twenty-nine states did not adopt a family cap; 21 states did. Of the 21 states that imposed such a cap, eight are southern states. Similar to Table 4, we find race to be a strong predictor of the imposition of a family cap in the Soss et al. replication model (Table 5), 


\section{Table 5. State Policy Choices Analyzed as Separate Dimensions: Family Cap}

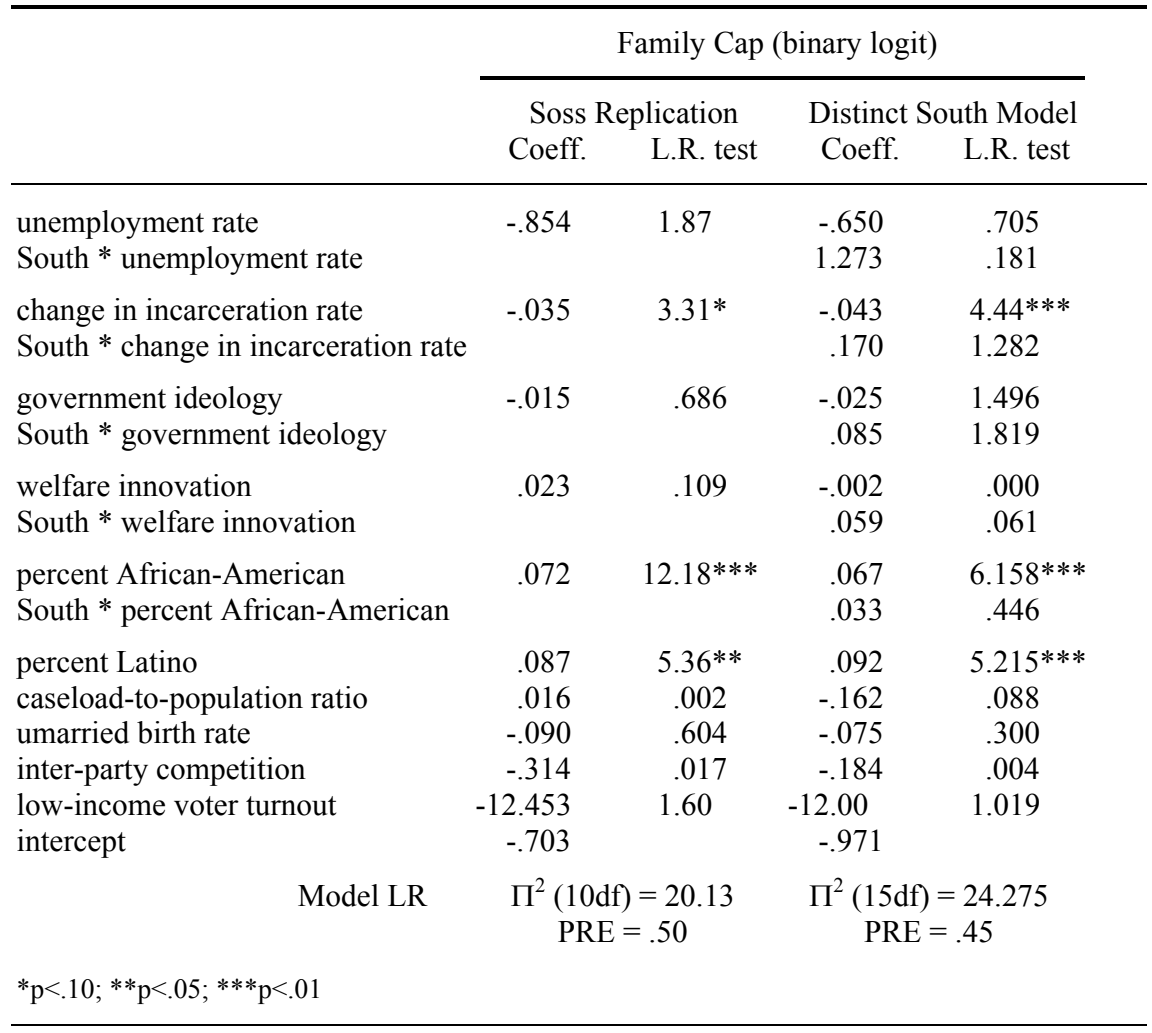

and in the distinct south model we find no discernable differences in the impact of race on the decision to adopt a family cap. Similarly, we find that the weak, negative relationship between incarceration rates and the dependent variable does not vary by region of the country.

\section{Conclusion}

The purpose of this research is to determine whether the factors driving state policy choices under TANF are different for southern states than for the rest of the nation. In general, we find little support among southern states for five of the six theoretical approaches suggested by Soss et al. (2001), indicating that the south is not terribly distinct from the rest of the country. The one theoretical approach that does seem to matter consistently is the social control explanation. This is consistent with traditionalistic political culture, 
which is the predominant culture found in the southern states. Race is also important, but is no more important as an explanatory factor in the south than it is in the rest of the country. While V.O. Key saw race as the driving force in southern politics, the south may not be unique when it comes to welfare policy specifically or in other policy areas generally.

Our findings for the ideological explanations are counterintuitive to our hypotheses. While we hypothesized that more liberal states would be less restrictive, the relationship is reversed in the southern states. We suspect that there are mitigating factors at work; state wealth or political culture may be important variables. The original Soss et al. work did not include such measures, and since our goal here was to test the same model for southern states, we likewise do not include these measures. However, we believe that revised models are appropriate fodder for future research.

\section{NOTES}

${ }^{1}$ We wish to thank Joe Soss, American University, for his kind permission to employ the dataset from the original work in this analysis.

${ }^{2}$ Mississippi, for example, began pilot programs in the early 1990s that included job training and work requirements.

${ }^{3}$ See Soss et al. (2001) for specific definitions and data sources for each of the independent variables used in this analysis.

${ }^{4}$ Although Soss et al. employed Stata 6.0 as their statistical package, the present analysis uses SPSS 13.0. Our attempts to replicate the original findings were largely successful, although both the coefficients and standard errors from our efforts differ slightly from the original analysis; we attribute these differences to the use of an alternative software package. The most important distinction is with the intercepts. Our intercepts differ numerically because in the creation of the interactive terms we centered each of the variables in the model. The process of centering the variables has the effect of reducing multicollinearity in interactive terms (Friedrich, 1982).

${ }^{5}$ Our "South" definition includes the states of North Carolina, South Carolina, Georgia, Florida, Alabama, Mississippi, Tennessee, Louisiana, Arkansas, and Virginia.

${ }^{6}$ In order to assess statistical significance of the individual coefficients we rely on the likelihood ratio test advocated by Hosmer and Lemeshow (1989). They note that the key issue in testing the significance of a coefficient is "[d]oes the model that includes the variable in question tell us more about the outcome (or response) variable than does a model that does not include that variable"? (p.12). This is also consistent with Menard's (2002, 42-43) advice that, when faced with large logit coefficients and the accompanying inflated standard errors which lowers the Wald statistics, to avoid failures to reject null hypotheses when they are false one should use the likelihood ratio test of the difference of models with and without that parameter. Thus the likelihood ratio columns contain the value of the change in the model $\mathrm{X}^{2}$ that would result from the deletion of that individual coefficient. 


\section{REFERENCES}

Borooah, Vani K. 2001. Logit and Probit: Ordered and Multinominal Models. Sage University Paper Series on Quantitative Applications in the Social Sciences, 07-138. Thousand Oaks, CA: Sage.

Brace, Paul, and Aubrey Jewett. 1995. The State of State Politics Research. Political Research Quarterly 48:643-681.

Breaux, David A., and John C. Morris. 2001. Assessing the Utility of Political Culture in Explaining Interstate Variation in Policy Outcomes: The Case of TANF. Paper presented at the 73rd Annual Meetings of the Southern Political Science Association, Atlanta, GA, November.

Breaux, David A., Christopher M. Duncan, C. Denise Keller, and John C. Morris. 2002. Welfare Reform, Mississippi Style: Temporary Assistance for Needy Families and the Search for Accountability. Public Administration Review 62:86-97.

Breaux, David A., Christopher M. Duncan, C. Denise Keller, and John C. Morris. 1998. Blazing the TANF Trail: The Southern Mind and Welfare Reform in Mississippi. American Review of Politics 19:175-189.

Breaux, David A., Christopher M. Duncan, John C. Morris, and Rodney E. Stanley. 2000. Explaining Variation in Welfare Benefits Across The Fifty American States: The Utility of Political Culture. Paper presented at the 72nd Annual Meeting of the Southern Political Science Association in Atlanta, GA, November 8-11.

Breaux, David A., Christopher M. Duncan, and John C. Morris. 2000a. An Examination of Welfare Reform in the 50 American States and the South: the Utility of Political Culture. Paper presented at the Twelfth Citadel Symposium on Southern Politics, Charleston, SC, March.

Burke, Vee. !997. Welfare Reform. Congressional Research Service Issue Brief. Washington, DC: Library of Congress.

Elazar, Daniel J. 1984. American Federalism: A View from the States, 3rd ed. New York: Harper \& Row.

Friedrich, R.J. 1982. In defense of multiplicative terms in multiple regression equations. American Journal of Political Science 26:797-833.

Gilens, Martin. 1999. Why Americans Hate Welfare: Race, Media, and the Politics of Anti-Poverty Policy. New Haven, CT: Yale University Press.

Gray, Virginia. 1973. Innovation in the States: A Diffusion Study. American Political Science Review 67:1174-1185.

Hicks, Alexander M., and Duane H. Swank. 1992. Politics, Institutions, and Welfare Spending in Industrialized Democracies, 1960-82. American Political Science Review 86:658-675.

Hill, Kim Quaile, Jan E. Leighley, and Angela Hinton-Andersson. 1995. Lower-Class Mobilization and Policy Linkages in the U.S. States. American Journal of Political Science 39:75-86.

Holbrook, Thomas M., and Emily Van Dunk. 1993. Electoral Competition in the American States. American Political Science Review 87:955-962.

Hosmer, D.W., and S. Lemeshow. 1989. Applied Logistic Regression. New York: Wiley.

Howard, Christopher. 1999. The American Welfare State, or States? Political Research Quarterly 52:421-442.

Key, V.O., Jr. 1949. Southern Politics in State and Nation. New York: Knopf.

Liebschutz, Sarah F. 2000. Managing Welfare Reform in Five States: The Challenge of Devolution. Albany, NY: Rockefeller Institute Press. 
Lindblom, Charles E. 1959. The Science of Muddling Through. Public Administration Review 19:79-88.

Mead, Lawrence M., ed. 1997. The New Paternalism: Supervisory Approaches to Poverty. Washington, DC: Brookings.

Mead, Lawrence M. 1992. The New Politics of Poverty: The Non-Working Poor in America. New York: Basic Books.

Menard, Scott. 2001. Applied Logistic Regression Analysis. Sage University Paper Series on Quantitative Applications in the Social Sciences, 07-106. Thousand Oaks, CA: Sage.

Mettler, Suzanne. 2000. States' Rights, Women's Obligations: Contemporary Welfare Reform in Historical Perspective. Women \& Politics 21:1-34.

Mizruchi, Ephraim H. 1983. Regulating Society: Beguines, Bohemians, and Other Marginals. Chicago: University of Chicago Press.

Nathan, Richard P., and Thomas L. Gais. 1999. Implementing the Personal Responsibility Act of 1996: A First Look. Albany, NY: Rockefeller Institute of Government.

Orr, Larry L. 1976. Income Transfers as a Public Good: An Application to A.F.D.C. American Economic Review 66:359-371.

Piven, Frances Fox, and Richard A. Cloward. 1993. Regulating the Poor: The Functions of Public Welfare. New York: Vintage Books.

Rector, Robert E., and Sarah E. Yousef. 1999. The Determinants of Welfare Caseload Decline. Report No. 99-04. Washington, DC: The Heritage Foundation for Data Analysis, Heritage Foundation.

Soss, Joe, Sanford F. Schram, Thomas P. Vartanian, and Erin O’Brien. 2001. Setting the Terms of Relief: Explaining State Policy Choices in the Devolution Revolution. American Journal of Political Science 45:378-395.

Suttles, Gerald D., and Mayer N. Zald, eds. 1985. The Challenge of Social Control: Citizenship and Institution-Building in Modern Society. Norwood, NJ: Aldex Publishing.

Walker, Jack L. 1969. The Diffusion of Innovations Among the American States. American Political Science Review 63:880-899.

Wright, Gerald C., Jr. 1976. Racism and Welfare Policy in America. Social Science Quarterly 57:718-730. 